\title{
La teoría en la educación biblio- tecológica: directrices básicas para su enseñanza
}

\author{
Jaime Ríos Ortega *
}

Artículo recibido:

18 de noviembre de 2005.

Artículo aceptado:

13 de junio de 2006.

\section{RESUMEN}

En este artículo se demuestra que no obstante la discusión durante varias décadas del problema entre la "teoría" y la "práctica", así como de la importancia que reviste la primera para orientar la formación de bibliotecólogos, ha predominado sin embargo el enfoque de la educación técnica. En relación con ello, se sistematizan únicamente tres directrices metodológicas, en lo fundamental derivadas de la enseñanza de las ciencias, a partir de las cuales es factible abordar la enseñanza de la disciplina bibliotecológica y superar algunos de los problemas que conlleva la enseñanza de carácter técnico. La primera directriz tiene como premisa que la bibliotecología se construye a partir de fenómenos,

* Centro Universitario de Investigaciones Bibliotecológicas de la UNAM, México. jrio@servidor.unam.mx

INVESTIGACIÓN BIBLIOTECOLÓGICA, Vol. 21, Núm. 42, enero/junio, 2007, México, ISSN: 0187-358X. pp. 109-142 
conceptos y teorías, la segunda destaca el papel fundamental de la historia intelectual de los conceptos y las teorías bibliotecológicas, y finalmente la tercera se centra en el cambio conceptual de los estudiantes de bibliotecología.

Palabras clave: Enseñanza de la bibliotecología; Educación bibliotecológica, Didáctica de la bibliotecología.

\section{ABSTRACT \\ Theory in library science: basic guidelines for its teaching \\ Jaime Rios Ortega}

It is shown that, notwithstanding several decades of discussion on the problem of "theory" and "praxis", and the importance of the former for giving direction to library science education; the latter, technical education, has predominated. Thus, only three methodological guidelines are systematized which derive fundamentally from the teaching of science, on the basis of which it will be possible to approach the teaching of the library science discipline and to overcome some of the problems associated with the teaching of a technical character. The first guideline holds that library science is built upon phenomena, concepts and theories. The second one underlines the fundamental role played by the intellectual history of concepts and library science theories. And the third one centers on the conceptual change undergone by library science students.

Keywords: Library science teaching; Library science education; Library science didactics.

\section{INTRODUCCIÓN}

T a enseñanza de la bibliotecología ha transitado desde una perspectiva $\mathcal{L}$ didáctica centrada en las técnicas hasta una concepción didáctica que
reconoce el estatus epistémico de la disciplina. Esto último se ha enunciado 
de diferentes modos y con ello se ha esperado fortalecer el campo teórico de la disciplina, la formación de los bibliotecólogos y su identidad profesional.

Sin embargo, aunque se ha subrayado la preocupación por concretar este tránsito, ha sido recurrente señalar que el enfoque de formación predominante se ha orientado hacia los aspectos técnicos, tecnológicos y procedimentales de la práctica profesional. En consecuencia, no se ha desarrollado una didáctica de la bibliotecología cuyo campo de acción sea, en una de sus dimensiones, la elaboración de directrices intelectuales que permitan enseñar a partir de la teoría con la preocupación puesta en los problemas cognoscitivos e ideales explicativos de la disciplina.

\section{LA “TEORÍA”, LA “PRÁCTICA” Y LOS MÉTODOS DE ENSEÑANZA EN LA BIBLIOTECOLOGÍA}

A la didáctica se la identifica, en su concepción simple y más inmediata, con los métodos de enseñanza, y aunque al analizar los problemas que giran en torno a la formación de los bibliotecólogos se encuentra un importante número de variables sociales, culturales, económicas, etcétera, se espera que una parte sustantiva de los problemas se resuelvan con una atractiva y suficiente formación o actualización de los profesores en cuanto a métodos de enseñanza, pues, finalmente, la didáctica no puede dejar de responder a la pregunta: ¿cómo enseñar bibliotecología?

La didáctica no se reduce ni se subsume en los métodos de transmisión. El planteamiento como tal es retrógrado hoy día. ${ }^{1}$ De hecho se constata que las diferentes ciencias han elaborado didácticas sumamente especializadas: didáctica de la historia, didáctica de la lingüística, didáctica de la biología, etcétera, e incluso con enfoques diferentes al abordar la enseñanza del objeto de estudio, pero dentro del campo específico de su didáctica particular. ${ }^{2}$

Autores como Sabor, en la década de los 60 del siglo pasado, pensaban que era necesario construir no tan sólo una didáctica sino una pedagogía bibliotecológica, ya que:

1 Dado que se ha ampliado el campo teórico de los problemas que trata la didáctica, existen autores que no dudan en proponerla como una ciencia. Véase: Ángel Díaz Barriga, "La investigación en el campo de la didáctica: Modelos históricos", en Perfiles Educativos 20, núm. 70 80: 5-25. También, para revisar aspectos relativos a la amplitud de los problemas que trata la didáctica, véase: José Contreras Domingo, Enseñanza, currículum y profesorado: Introducción crítica a la didáctica (España: Akal, 1994), 13-50 y 99-146.

2 Desde la década de los cincuenta se distinguía entre didáctica general y didácticas especiales. La primera trataba de generar enunciados universales para todo tipo de enseñanza, mientras que las otras se concretaban a los contenidos específicos de las disciplinas. Véase: Karl Stöker, Principios de didáctica moderna (Argentina: Kapelusz, 1964), 5-7. 
Como se ha dicho, la bibliotecología no ha creado un método especial de enseñanza. Ha tomado de la didáctica tradicional y en algunas oportunidades los ha buscado en otras disciplinas (...) sin introducir variantes notables. Así se explica lo limitado de las contribuciones que se ocupan del tema. En las obras tradicionales y por cierto muy valiosas que tratan del problema de esa enseñanza, apenas si se dedican algunas páginas a la metodología, las cuales están a menudo llenas de dudas, lamentaciones y propuestas aproximativas, sin que sea fácil obtener de ellas una ayuda concreta. ${ }^{3}$

De acuerdo con Nassif, el itinerario de trabajo de investigación de la pedagogía bibliotecológica abarcaría los temas que a continuación se enumeran:

1. Conceptos, fines y funciones de la educación bibliotecológica.

2. Grados de la educación bibliotecológica.

3. Sistemas e instituciones para la formación bibliotecológica.

4. Planes y programas de estudios adecuados a esa formación.

5. Metodología de la enseñanza bibliotecológica, según los objetivos de la formación teórica y técnica.

6. Formas de aprendizaje bibliotecológico.

7. Métodos de evaluación del rendimiento. La promoción de los alumnos.

8. Las enseñanzas no bibliotecológicas en la formación bibliotecológica. El problema de la formación general en relación con la profesión bibliotecológica.

9. Formación y reclutamiento del personal docente.

10. Reclutamiento de los alumnos. La orientación educativa y profesional en las escuelas de bibliotecología.

11. Actividad de los centros de formación bibliotecología en el perfeccionamiento y actualización de los bibliotecarios en servicio. Los cursos para graduado.

12. Contribución y medios de los centros de educación bibliotecológica para la educación en otros niveles y en la cultura popular. ${ }^{4}$

En las décadas siguientes no llegó a concretarse un proyecto de esa naturaleza y los temas propuestos se han estudiado como problemas fundamentales de la educación bibliotecológica, pero no se generó un campo disciplinario tan ambicioso como el de una pedagogía ad hoc. No obstante, los temas antes enumerados no han perdido relevancia y debieran forman parte de la agenda de investigación de diferentes países, incluido México, obviamente.

3 Josefa E. Sabor, Métodos de enseñanza de la bibliotecología (París: UNESCO, 1968), 65.

4 Ricardo Nassif, "Fundamentos de pedagogía y metodología: Estudio preliminar para una pedagogía bibliotecológica" En Josefa E. Sabor, Métodos de enseñanza de la bibliotecología (París: UNESCO, 1968), 30-31. 
El punto imprescindible han sido los métodos de enseñanza. Para 1968, en que Sabor hacía énfasis en lo inadecuado de la enseñanza de la bibliotecología y el tratamiento confuso de sus métodos de enseñanza, solamente actualizaba un aspecto del problema que Periam Danton en 1950 había señalado a través de dos afirmaciones más amplias respecto a los métodos de enseñanza en las escuelas de bibliotecología. La primera de ellas se refiere al hecho de que en la enseñanza superior se requiere incorporar técnicas especiales que tiendan a darle al estudiante los conocimientos prácticos básicos.

En la segunda afirmación destaca:

... existe inevitablemente cierto conflicto, en la filosofía de la educación, entre el enfoque teórico y general de la enseñanza, por un lado, y el práctico y específico por el otro. Este conflicto no han podido resolverlo enteramente ni siquiera las escuelas más antiguas y de vida más fructífera. [...] la preocupación fundamental de la enseñanza se centra todavía en lo concreto, lo técnico y práctico, excluyéndose virtualmente los aspectos teóricos generales. ${ }^{5}$

Asimismo, Danton resumió las tendencias que habían orientado la formación de los bibliotecólogos y que han sido inherentes a los métodos de enseñanza. Las dos tendencias que se presentan como opuestas, son por una parte de carácter "práctico" y, por otro, de orden "teórico". Danton explica estas tendencias del siguiente modo:

Los que sostienen el punto de vista $<<$ práctico $>>$ afirman que la bibliotecología no tiene un cuerpo general de conocimientos, y que el futuro bibliotecario puede aprender solamente mediante la experiencia, ya sea en una biblioteca ya en clases de laboratorio, de referencia o catalogación. Los que sostienen el punto de vista teórico, $[\ldots]$ argumentan que existe un cuerpo general de conocimientos que constituye la bibliotecología y que el futuro bibliotecario estará mejor preparado para el ejercicio de la profesión si comprende las teorías y los principios generales que fundamentan materias tales como la administración, selección de libros y clasificación, siendo capaz de aplicarlos a situaciones concretas. ${ }^{6}$

Como veremos más adelante, apelar al uso de los métodos de enseñanza de la bibliotecología orientados hacia la formación práctica o teórica, no ha perdido vigencia en la literatura especializada. Sin embargo, es posible observar que a pesar de las críticas hechas a la formación orientada hacia la "práctica", ésta se ha impuesto durante varias décadas.

5 Periam Danton, La formación profesional del bibliotecario (París: UNESCO, 1950), 25.

6 Ibid. 
En los años treinta, Butler fue uno de los primeros en señalar, en estilo duro y sin concesión, lo que podrían considerarse los resultados de la formación práctica:

A diferencia de quienes trabajan en otros campos de la actividad social, el bibliotecario, cosa rara, no muestra ningún interés por los aspectos teóricos de su profesión. Al parecer, es inmune a esa curiosidad que en las restantes disciplinas induce al hombre a orientar sus tareas, de un modo u otro, hacia el cauce por donde fluye la corriente principal de la vida humana. Aparentemente, el bibliotecario se mantiene aislado en la simplicidad de su pragmatismo: la racionalización de cada uno de los procedimientos técnicos inmediatos parece satisfacer su inquietud intelectual. A decir verdad, el menor intento de generalizar esas racionalizaciones para desarrollar una filosofía de su profesión le parecería no sólo fútil sino decididamente peligroso. Tiene clara conciencia de los preciosos valores objetivos implícitos en todo contacto del individuo con la herencia cultural de la humanidad, por consiguiente, se muestra temeroso ante el advenimiento de la ciencia, pues desconfía de su fría objetividad. ${ }^{7}$

Por supuesto Butler representa la perspectiva de la Universidad de Chicago la cual irrumpe en el contexto educativo bibliotecario de finales de los veinte con la orientación hacia la investigación y la "teoría" al establecer la Graduate Library School. Según Shera, en la escuela de Chicago el ideal era: "La teoría y el método habrían de anteceder a la técnica".

Dado que es de vital importancia el programa escolar que se impulsa y la tendencia que conforma, es pertinente mencionar los objetivos que de dicho programa se reconocen en 1940 y, según menciona Shera, son los siguientes: ${ }^{9}$

1. Desarrollar una teoría o filosofía de la bibliotecología.

2. Extender y aplicar la búsqueda de principios guías que fueran aplicables a las varias subdivisiones de la bibliotecología.

3. Capacitar a los estudiantes competentes para: (a) desempeñar sus actividades profesionales de acuerdo con sus principios y filosofía; (b) enseñar las varias ramas de la bibliotecología sobre esa base, y (c) efectuar investigaciones que contribuyeran a clarificar mejor los principios y métodos de evaluar la práctica y a solucionar los problemas de una biblioteca.

4. Desarrollar en el estudiante una actitud crítica y experimental y a tener un punto de vista hacia la bibliotecología.

7 Pierce Butler, Introducción a la biblioteconomia, (México: Pax, 1971), 14 
5. Promover las publicaciones.

6. Incrementar la efectividad educativa de la biblioteca.

7. Desarrollar una mejor comprensión de los medios para comunicar ideas a través de los impresos, la radio y el cinematógrafo.

No es exagerado afirmar el carácter seminal de estos objetivos y puede constatarse su actualidad si se compara con algunos de los programas de formación de bibliotecólogos en México, como es el caso de la Escuela Nacional de Biblioteconomía y Archivonomía y El Colegio de Bibliotecología de la Universidad Nacional Autónoma de México.

Sabor consideraba, a finales de los sesenta, que se notaba una tendencia general a afirmar el valor de lo teórico y propiciar, "un predominio muy evidente sobre lo práctico, una jerarquización dentro de la armonía de ambas corrientes, siempre a favor de los principios sobre las normas prácticas". ${ }^{0}$ Asimismo, destacaba que:

La afirmación más general es que "armonía” es la verdadera clave del asunto, pero a la vez se insiste en que lo que el bibliotecario debe tener es una mente creadora y que el aprender de memoria y el hacer prácticas no son los mejores medios para alcanzarla. Es necesario que el bibliotecario sea capaz, en una situación dada, de reaccionar eligiendo el mejor camino llegando la solución más justa, no tanto por qué se le haya enseñado ese caso particular, cuanto porque conoce teorías y principios y tiene la suficiente seguridad de juicio para aplicarlos a cualquier tipo de situación. $^{11}$

Por lo señalado hasta aquí sobre las dos tendencias, es posible apreciar que los métodos de enseñanza debían seguir una u otra orientación y el problema fundamental era ¿en torno a cuál enfoque de formación ("práctico" o "teórico") se articulaban? tanto Danton en 1950 como Sabor en 1968, casi coinciden totalmente en los siguientes métodos o técnicas:

1. Lecciones o expositivas

2. Discusiones en clase

3. Trabajos prácticos o laboratorios

4. Prácticas en bibliotecas

5. Cursillos, mesas redondas y simposios

6. Problemas y casos

7. Seminarios

10 Sabor, Métodos, 82.

11 Ibid. 
8. Elaboración de monografías y bibliografías

9. Entrevistas y visitas

Con la incorporación masiva de los medios audiovisuales en la enseñanza desde los años setenta, el énfasis se dio aún más hacia la producción en dichos medios y la tendencia ha sido irreversible. ${ }^{12}$ No obstante, hay autores que hoy privilegian alguno de los métodos anteriores para apoyar la educación profesional de los bibliotecólogos, particularmente el estudio de casos, ${ }^{13}$ y es innumerable la bibliografía que promueve el uso de medios electrónicos y digitales.

No obstante, el foco de tensión entre prácticos y teóricos no ha desaparecido. Goldhor había aclarado desde 1948 el sentido de la enseñanza de la "teoría" en la enseñanza profesional y mencionaba la necesidad de que hubiera una estrecha relación entre la teoría y la práctica. Al respecto, enfatizaba que:

Sin la teoría, la práctica se vuelve caótica, mera colección de casos aislados e individuales. La teoría da sentido y unidad a lo que de otro modo serían casos aislados y específicos. Por otra parte, sin la práctica, la teoría se vuelve mera especulación. Las realidades de la práctica, la pura especulación, sirven de medida a la justeza de la teoría, y atienden asimismo a los problemas con que toda teoría tiene que tropezar por fuerza. ${ }^{14}$

Lo interesante de la cita de Goldhor es que no postula el predominio de un aspecto sobre el otro, sino que explica la función y la necesidad de complementar ambos aprendizajes.

Al paso de los años, no parece que se haya logrado romper el tipo de formación bibliotecológica de orientación "práctica" ya que en 1980 el problema continuaba discutiéndose y Morehead, por ejemplo, destacaba que era la consecuencia de que las universidades hubieran incorporado la enseñanza profesional bibliotecológica y matizaba que el dualismo representado por la teoría versus la práctica, conocimiento versus habilidades, o conocimiento básico versus aplicado, era un dualismo con el cual debía lucharse permanentemente en la educación profesional. ${ }^{15}$

12 Véase: Antonhy H. Thompson, Guía para la producción y la utilización de medios audiovisuales en la enseñanza de la bibliotecología y ciencia de la información (París: UNESCO, Programa General de Información y UNISIST, 1983).

13 Véase: Nancy J. Becker, Elizabeth B. Pollicino y Dennis H. Holtshneider, C.M., Challenges in Libranship: A Casebook for Educators and Professionals (USA: Scarecrow Press, 2003).

14 Herbert Goldhor, "Some Thoughts on the Curriculum of Library School", en School and Society 67, Jun 12, p. 434-35. Citado por Periam Danton, La formación profesional del bibliotecario (París: UNESCO, 1950), 26. 
Ostler, Dahlin y Willardson, analizaron los factores que contribuyeron a cerrar más de 15 escuelas de graduados en Estados Unidos durante la década de los ochenta del siglo pasado. De su estudio, entre otros aspectos, llama la atención que en sus propuestas para reformar el currículo de los programas de maestría en bibliotecología, marquen destacadamente el fuerte peso que debe darse a la teoría. ${ }^{16}$

Por su parte, Auld ${ }^{17}$ ponía en primer lugar, de los siete imperativos para la educación bibliotecológica que trata, la necesidad de equilibrar la polaridad que representa el conflicto entre las expectativas profesionales versus las académicas; es decir, expresa nuevamente el permanente conflicto entre la formación "práctica" y la "teórica”. En segundo lugar trata el problema de las denominaciones de la disciplina y las implicaciones que esto tiene para la identidad profesional. Esto último es relevante señalarlo, porque en la literatura del tema, ambos problemas comenzarán a tratarse de modo contiguo, como en el caso de Stieg, quien reproduce los elementos básicos de la problemática antes señalada en dos de las nueve preguntas esenciales que se plantea; las dos preguntas a las que me refiero son: ¿cuál es el balance adecuado entre educación y entrenamiento? y ¿cuáles son los conocimientos básicos de la profesión? ${ }^{18}$ En este caso, "educación” tendrá como referente la teoría y la investigación, así como "entrenamiento" se referirá a la práctica o ejercicio técnico de la profesión.

En lo que toca a métodos de enseñanza Stieg menciona que "Inseparable del contenido de un curso es el método por el cual es enseñado; el método puede ser que haga la diferencia entre un buen curso y un mal curso"19 También destaca que los estándares de acreditación de la American Library Association (ALA) guardan silencio en lo que se refiere a los métodos apropiados de enseñanza, pero hace presión respecto a la innovación e incorporación de laboratorios de cómputo y audiovisuales. Asimismo reitera la importancia del estudio de caso, el método de lectura, los programas de cómputo emuladores y la filmación de clases. ${ }^{20}$ Llama la atención que no hay diferencias sustantivas respecto a los métodos que, desde 1950 y 1968, Danton y Sabor ya mencionaban, salvo los programas de cómputo emuladores y la filmación de clases.

16 Larry J. Ostler, Therrin C. Dahlin y J.D. Willardson, The Closing of American Library Schools: Problems and Opportunities (USA: Greenwood Press, 1995), 67.

17 Lawrence W.S. Auld, "Seven Imperatives for Library Education”, en Library Journal, may 1 (1990): 55-57.

18 Véase: Margaret F. Stieg, Change and Challenge in Library and Information Science Education, (USA: American Library Association, 1992), 6-7.

19 Ibid., 119.

20 Ibid., 120. 
Stieg se refiere a los estándares de la ALA de 1972. Sin embargo en los estándares adoptados por el Consejo de la ALA, en enero de 1992, tampoco se mencionan los métodos de enseñanza de modo concreto.

En el apartado I. Misión, Metas y Objetivos de los Standards for Accreditation of Master's Programs in Library E Information Studies, se dice que los programas educativos deben reflejar, en términos de resultados, diferentes aspectos, importantes todos ellos. Sin embargo, respecto al equilibrio deseado entre "teoría" y "práctica" es interesante constatar que no contiene menciones explícitas sobre la "teoría", aunque sí se refiere puntualmente a la investigación original de la bibliotecología y de otras disciplinas.

$\mathrm{Al}$ respecto señalan:

- la filosofía, principios, y ética del campo

- la importancia de la investigación para el avance del conocimiento del campo

- la importancia de las contribuciones de otros campos de conocimiento para los estudios de bibliotecología e información ${ }^{21}$

Asimismo, conviene mencionar que en el apartado II. Currículum de los estándares antes mencionados, se puntualiza, entre otros tópicos, dos referentes; uno que apuntan hacia la teoría y la investigación, así como otro que está articulado al campo profesional, pero apoyado en el primero:

- énfasis en desarrollar un cuerpo de conocimientos que refleje los avances de la investigación básica y aplicada

- provee orientación para el futuro desarrollo del campo ${ }^{22}$

En el apartado ya señalado se indica que el currículum debe proveer al estudiante oportunidades para construir un programa coherente de estudio que tome en cuenta sus necesidades individuales, metas y aspiraciones, así como desarrollar las competencias necesarias para una carrera productiva. Incluye también la cooperación con otros programas, talleres interdisciplinarios e investigación y oportunidades de experimentación. Asimismo se advierte que las experiencias de aprendizaje especializado serán construidas a partir de los fundamentos generales de la bibliotecología y estudios de

21 "American Library Association's Standards for Accreditation of Master's Programs in Library \& Information Studies" en Larry J. Ostler, Therrin C. Dahlin y J.D. Willardson, The Closing of American Library Schools: Problems and Opportunities (USA: Greenwood Press, 1995 ), 84. sociedad (multicultural, multiétnica y multilingüe) y el desarrollo profesional. 
la información y agrega que: "El diseño de las experiencias de aprendizaje especializado tomará en cuenta las clases de conocimiento y competencias desarrollados por las organizaciones profesionales relevantes". ${ }^{23}$

Derivado de lo anterior, son conceptos como: investigación, interdisciplina, cuerpo de conocimientos, construcción de programa, diseño de experiencias de aprendizaje, necesidades individuales, experimentación, así como competencias, que requerirían un conjunto de métodos de enseñanza con énfasis destacado hacia la teoría de la disciplina bibliotecológica y en menor medida al ámbito profesionalizante.

Algunos de estos elementos ya estaban presentes desde 1972 en planteamientos importantes como los de Shera respecto a la función de la investigación, el cual enumeraba como uno de los objetivos del programa profesional, la adquisición de:

3. Un conocimiento de los principios y métodos de investigación aplicados a la búsqueda de problemas bibliotecológicos, junto con la habilidad de evaluar los resultados de la investigación, especialmente de la investigación en bibliotecología desde el punto de vista de la adecuación y confiabilidad de los métodos usados y la validez de los resultados obtenidos. ${ }^{24}$

\section{Agregaba también que:}

... el bibliotecario debe tener algún conocimiento de los procesos por los cuales avanza el conocimiento del proceso de investigación. Esto es esencial debido a tres razones fundamentales: (1) él mismo puede, en el curso de su carrera profesional, querer involucrarse en algunas investigaciones propias, aunque cuando no sean más que simples evaluaciones de la efectividad de una sola operación; (2) puede corresponderle, ciertamente, evaluar la investigación de otros y debe, por lo tanto, ser capaz de separar el trigo de la paja; y (3) a menos que tenga cierta apreciación del significado de la investigación y los medios por los cuales ésta se conduce, no podrá a apreciar las necesidades de un importante segmento de su clientela. ${ }^{25}$

La ALA da una presencia importante a la investigación en los estándares y tiene como base situaciones y razones diferentes a las formuladas por Shera, pero ello no quita relevancia a lo expresado por el autor antes citado.

Respecto al estándar que indica construir el programa académico del alumno a partir de sus necesidades y el diseño de experiencias de acuerdo

23 Ibid., 85-86.

24 Jesse Shera, Fundamentos de educación bibliotecológica (México: UNAM, CUIB, 1990), 370.

25 Ibid., 372. 
con sus intereses, dicho estándar tiene como condición necesaria el concepto del aprendizaje centrado en el alumno, el cual ya se había expresado, aunque parcialmente, en el documento de UNESCO titulado Guidelines for Curriculum Development in Information Studies. ${ }^{26}$

Los dos conceptos novedosos en los estándares son interdisciplina y competencias que cobran peso importante durante la década de los ochenta y, a partir de los noventa, son parte fundamental de la investigación bibliotecológica, el primero, y de la educación bibliotecológica, el segundo. ${ }^{27}$

No obstante lo ya mencionado, autores como Saracevic han postulado que las normas de acreditación de la ALA actualizadas en 1992, continúan con la tradición de la enseñanza técnica iniciada en 1887, la cual no toma en cuenta la teoría. Esto lo critica severamente, ya que:

Con la ausencia de la teoría, el modelo técnico se deterioró fácilmente tanto en lo vocacional como en la educación profesional. El modelo de educación técnica es completamente diferente del modelo de investigación, donde la educación se concentra bajo los principios teóricos de una actividad. ${ }^{28}$

Saracevic reitera que una de las consecuencias negativas, producto del modelo de educación técnica y el currículum básico que se enseñó desde 1887, resultó inhóspito para la teoría de los fenómenos y los procesos. ${ }^{29}$ Asimismo señala que:

Los esfuerzos por cambiar la educación bibliotecológica técnica hacia el modelo de investigación e incorporar materias de fundamentos que contienen teorías acerca de los procesos no fue exitosa, básicamente, porque no fue aceptada. Lamentablemente, para toda la educación bibliotecológica, un cambio de paradigma no ocurrió. El COA [Committee on Accreditation] nunca lo consideró. ${ }^{30}$

De acuerdo con Saracevic, los efectos del predominio de la visión formativa técnica han sido desastrosos en la educación bibliotecológica y culminaron,

26 Véase el párrafo número 17 de Guidelines for Curriculum Development in Information Studies (París: UNESCO, UNISIS, 1978), 8.

27 Véase: Library Trends 45, num. 2 (1996): 129-336. El fascículo se titula: "Navigating Among the Disciplines: The Library and Interdisciplinary Inquiry". Véase también: Sajad ur Rehman, Preparing the Information Professional: An Agenda for the Future (USA: Greenwood Press, 2000). El escenario de trabajo que plantea el autor toma como base el enfoque de competencias para desarrollar y presentar su estudio.

28 Tefko Saracevic, "Closing of Library in North America: What Role Accreditation?" Libri 44, no. 3 (1994): 194-95. 
junto con otros factores, en la desaparición del 25\% de las escuelas de graduados en Estados Unidos en los años ochenta. Es inminente, en su perspectiva, reformular nuevamente las normas de acreditación y transitar hacia un modelo de universidad que no esté centrada exclusivamente en la enseñanza de las actividades profesionales, y en consecuencia no se permanezca sin cultivar y fomentar el desarrollo del conocimiento teórico de la disciplina.

De modo que no se trata únicamente de abrir espacios dentro de la enseñanza técnica, al estudio de la teoría bibliotecológica y los fundamentos, o de agregar asignaturas de investigación en los currículos de las escuelas. Se pretende esencialmente superar el enfoque de enseñanza técnica por un enfoque de disciplina teórica, es decir, un enfoque basado en la comprensión y explicación de los fenómenos bibliotecológicos a partir de los fundamentos conceptuales de la disciplina.

Gorman en su artículo The Future for Library Science Education menciona que los cambios en los fundamentos teóricos del conocimiento que sostendrán los currículos de las escuelas serán mínimos, pero que los cambios tecnológicos ocurrirán con gran rapidez. Por lo tanto las escuelas deberán adaptarse a esos cambios y deberán ser flexibles, individualizadas y autorreguladas. Entre otros aspectos subraya que la educación y la capacitación son actividades para toda la vida y requieren de integrar cercanamente las habilidades profesionales y académicas. ${ }^{31}$ De nueva cuenta, los métodos de enseñanza quedan implícitos.

Pemberton y Nugent postularon que la "teoría" que se enseña en las escuelas debe aspirar a la unificación teórica, a partir de un currículum convergente, que presentan las diferentes disciplinas cuyo campo de estudio es la información. Los elementos que hacen posible esta unificación los constituyen los puntos de intersección dados por conceptos / funciones que son comunes a estos campos, tales como: ciclo de vida, conservación, almacenamiento y recuperación de información, representación de la información, etcétera, e insisten en que es fundamental privilegiar la enseñanza con énfasis en teorías más que en técnicas, de modo tal que se tenga una perspectiva más amplia en los marcos de comprensión de los estudiantes para integrar el aprendizaje de los campos profesionales emergentes. ${ }^{32}$

Tanto en Gorman como Pemberton y Nugent, se aprecia que el sentido de teoría y campo de estudio, tienen en realidad como referente el campo profesional y están implícitos los métodos de enseñanza que se requieren pa-

31 G. E. Gorman, “The Future for Library Science Education”, en Libri 46 (1999): 8.

32 Pemberton, Michael, J. y Cristine R. Nugent "Information Studies: Emergent Field, Convergent Curriculum", en Journal of Education for Library and Information Science 36, no. 2 (spring 1995): $126-38$. 
ra concretar las propuestas que desarrollan. Pero no hay duda que hay un reconocimiento pleno de la importancia que guarda la teoría y sus principios, así como una visión sobre la práctica más inclusiva que toma en consideración a la academia y el campo profesional.

En el contexto nacional Lafuente y Morales propusieron organizar el currículo a partir de presentar una teoría integral de la bibliotecología y los fenómenos que abarca; estos fenómenos están enunciados en la definición que ofrecen, según la cual la bibliotecología es la ciencia que estudia "el registro y flujo del conocimiento y la información; así como la circulación social de los medios que la contienen para hacer posible su uso y organización". 33

También mencionan que:

... la enseñanza de los principios y teorías esté orientada a la comprensión de la naturaleza de los fenómenos, con la intención de que el alumno se apropie de los conocimientos suficientes para identificar el fenómeno, pero atendiendo en todo momento a que sea capaz de vincular estos conocimientos con su aplicabilidad pragmática. $^{34}$

Agregan que el contenido de algunas asignaturas atendería la enseñanza de lo que son los fenómenos, los principios y las teorías, para que el alumno aprenda el desarrollo de la disciplina, cuáles son los supuestos y fundamentos y el valor que tiene el conocimiento bibliotecológico. Además, de acuerdo con estos autores:

Es necesario también, enseñar que los fenómenos bibliotecológicos se presentan en un entorno social determinado y que durante el transcurso de su evolución han generado instituciones relevantes para la sociedad que aplican el conocimiento bibliotecológico y representan un aspecto fundamental para la preservación y difusión de la cultura; ${ }^{35}$

La visión que presentan estos autores no se había dado en la literatura especializada publicada en el país. El cambio de perspectiva puede explicarse como respuesta a tres tendencias predominantes en los programas profesionales de educación bibliotecológica en México: 1. La formación basada en la organización técnica de las bibliotecas, 2. La formación con fuerte preponderancia en las tecnologías de automatización y 3. La administración.

33 Ramiro Lafuente López y Estela Morales Campos, "Reflexiones en torno a la enseñanza de la bibliotecología”, en Investigación bibliotecológica 6, no. 12 (enero-junio 1992): 25. 
Hay también una variante de estos autores que es importante resaltar ya que el referente de "teoría" y "principios", no está en el campo profesional sino en las entidades estrictamente disciplinarias.

En relación con los métodos de enseñanza, Morales destaca en su libro Educación bibliotecológica en México 1915-1954, que se manifestaba un vacío de información al respecto y a partir de los testimonios que recoge en su estudio en comparación con lo que a finales de los años ochenta observa, destaca que por una parte se tiene al profesor verbalista y que propicia los apuntes, así como al profesor preocupado por formar una actitud crítica de los estudiantes. Añade que una deficiencia persistente es la clase eminentemente práctica, las cuales

"se ejemplifican en el pizarrón, lo cual nos puede dar una realidad deformada en cuanto al objeto de estudio, y en cuanto al grado de dificultad de los problemas inherentes al objeto". ${ }^{36}$

Asimismo, comenta que otra característica manifestada en las escuelas de bibliotecología consiste en que :

... cuando se planea, se está pensando que tendrá alumnos, principalmente, a empleados de bibliotecas que primero tenían que cumplir con su horario y su carga de trabajo, por lo tanto el horario de clases es en la tarde, cargado hacia la noche, y en los trabajos extra clase, se tienen presente que los alumnos cuentan con un mínimo de horas para el estudio y la investigación, ya que salen del trabajo para

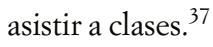

Bien puede decirse al respecto que después de tres lustros, ambas caracterizaciones no han perdido objetividad. Morales tampoco ha dejado de señalar la importancia de la formación del pensamiento crítico como medio de trabajo de las escuelas y al respecto ha escrito:

Independientemente del diseño curricular y el plan de estudios, las escuelas de bibliotecología deben privilegiar en sus métodos y técnicas de enseñanza actitudes y situaciones como:

a) La relación de investigación con la docencia.

b) El ejercicio del análisis y la crítica.

36 Estela Morales Campos, Educación bibliotecológica en México 1915-1954 (México: UNAM, CUIB, 1989), 56-7.

37 Ibid., 57. 
c) Una actitud de cambio y adaptación.

d) Un conocimiento de lo que se hace en el mundo. ${ }^{38}$

Por su parte, Rodríguez en su libro Formación bumanista del bibliotecólogo: hacia su recuperación, después de hacer el análisis de la educación bibliotecológica internacional y nacional, observaba que:

"La enseñanza que se ha impartido en la mayoría de las escuelas, hasta ahora, ha propugnado la repetición de actividades técnicas fomentando el uso de la tecnología, como si en su uso se encontraran los paradigmas de la disciplina." ${ }^{39}$

Hace también hincapié en que el mayor problema de la educación bibliotecológica es la falta de capacidad para trabajar con conceptos que contengan una fuerte carga de abstracción. Ya que:

Para la enseñanza de la bibliotecología se ha seguido un sistema de verdades "evidentes" que no se discuten, que se ven como verdades absolutas y no como productos del pensamiento humano y, por lo tanto, sujetas a replanteamientos y enriquecimiento constantes. ${ }^{40}$

A través de los planteamientos citados por Rodríguez se reitera que la enseñanza técnica, en efecto, no ha propiciado el cultivo y crecimiento de la teoría.

Con base en la revisión hecha de los diferentes autores e instituciones que han abordado directa o indirectamente el problema de la enseñanza bibliotecológica a través de la dicotomía "teórico" y "práctico", o bien refiriéndose específicamente a los métodos de enseñanza, e incluso a lineamientos curriculares, podemos apuntar que es inobjetable hoy día la necesidad de orientar la enseñanza de la disciplina teniendo como eje de trabajo la teoría que la constituye, diferenciándola del campo profesional. De ningún modo es excluyente un enfoque de esta naturaleza respecto a los problemas sociales y empíricos que le exige la sociedad resolver a los egresados de este campo de conocimiento.

Por el contrario, se ha manifestado de diferentes modos que un enfoque centrado en la enseñanza de la teoría fortalece una preparación profesional acorde con el avance las ciencias, así como los cambios y transformaciones de la profesión, la educación superior y la sociedad.

38 Estela Morales Campos, ¿Por qué estudiar bibliotecología? Ponencia presentada en la XVII Reunión del Consejo para Asuntos Bibliotecarios, Universidad Autónoma de Baja California Sur, 26 al 28 de abril de 2001. p. 8.

39 Adolfo Rodríguez Gallardo, La formación bumanista del bibliotecario: hacia su recuperación (México: UNAM, CUIB, 2001), 243-4. 


\section{LA BIBLIOTECOLOGÍA ENSEÑADA COMO DISCIPLINA TEÓRICA}

En literatura anglosajona especializada sobre bibliotecología y educación no existe el concepto "didáctica". Lo que en otras latitudes se estudia en torno a ella, una parte debe buscarse a través del concepto "currículum" y "psicología educativa" ${ }^{\text {", }}$ o bien "métodos de enseñanza". En la tradición alemana y latinoamericana, la didáctica ha tenido un sentido más práctico y normativo que se ha enriquecido en modo considerable por el avance de las ciencias y la atención que se ha prestado a su enseñanza.

Fueron dos los acontecimientos que ampliaron la perspectiva de estudio de la didáctica, a partir de la enseñanza de la ciencia.

El primero de ellos está dado por la publicación de las conclusiones de la Conferencia de Woods Hole en Estados Unidos, en 1960, a cargo de Gerome Bruner. Los puntos básicos que se acordaron fueron los siguientes:

1. Destacar la importancia de la enseñanza de los conceptos de ciencia, además de la metodología.

2. Enseñar la naturaleza y estructura de la disciplina, y no los contenidos aislados.

3. Centrar el currículo en el alumno para que se convierta en actor del proceso en relación directa con los fenómenos y descubrir los conceptos y leyes.

4. Identificar al profesor como guía del proceso de enseñanza -aprendizaje. ${ }^{42}$

Desde entonces, las tres últimas décadas ha visto enormes esfuerzos internacionales por introducir la enseñanza de la ciencia en los currículos, tanto en el plano internacional como nacional.

El otro acontecimiento fue la publicación de La estructura de las revoluciones cientificas de T. S. Kuhn, ${ }^{43}$ que aportó una perspectiva diferente de comprender el trabajo de las comunidades epistémicas, a partir del estudio de su historia.

Destaco estos dos acontecimientos porque a partir del primero ellos se desarrollarán importantes campos de estudios para comprender los procesos cognoscitivos sobre el aprendizaje y, en consecuencia, para la enseñanza; del segundo, menciono que sirvió de base para comprender aún más la historia y el progreso de las ciencias.

Antes de abordar las directrices conviene anotar que existe una coincidencia en cuanto a lo que se debe enseñar: la teoría, los principios, la disciplina

41 Pertti Kansanen, "La Deutsche Didaktik", Revista de Estudios del Curriculum 1, núm. 1, (1998): 13-20.

42 Gerome Bruner, El proceso de la educación (Argentina: UTHEA, 1963).

43 T. S. Kuhn, La estructura de las revoluciones científicas (México: FCE, 1971). La primera edición en inglés data de 1961. 
bibliotecológica y sus objetos de estudio. El vacío que se detecta es el "cómo", si se toma como punto de partida el estatus epistemológico de las entidades teóricas de la bibliotecología.

Sin duda, los planteamientos de Kuhn, lo convirtieron en el autor más fructífero en el campo de la enseñanza de las ciencias. ${ }^{44}$ Sin embargo, existen otros autores tan relevantes como él, los cuales pueden rendir frutos importantes si se trabaja con sus concepciones sobre las ciencias y sus cambios o transformaciones, me refiero a Sthephen Toulmin ${ }^{45}$ y Larry Laudan, ${ }^{46}$ por mencionar a sólo dos pensadores imprescindibles en el campo de la historia y la filosofía de la ciencia.

Shera, a partir de la obra de Kuhn, interpretó un aspecto interesante para la investigación bibliotecológica al distinguir los fines cognoscitivos de los normativos:

Los paradigmas de la "ciencia normal" de la bibliotecología nuca han estado completamente articulados, pero por lo menos están presentes, y han sido aceptados por la comunidad bibliotecaria: conservación, educación, recreación, información, inspiración, y apreciación estética: estos mismos puede decirse que constituyen una especie de paradigma y expresado explícitamente o no, fundamentan el todo de la Public Library Inquiri. Pero dichos valores no son aceptables como una estructura para la investigación bibliotecológica. Se debe buscar más profundamente que la identificación de tales valores para la teoría de lo que es la bibliotecología en términos cognoscitivos más que normativos. ${ }^{47}$

Así como Shera, otros autores del ámbito bibliotecológico se han apoyado en la concepción de Kuhn, para explicar algunas de las características de las concepciones de ciencia en la disciplina, como es el caso de Grover y Glazier, ${ }^{48}$ Dick ${ }^{49}$ o Shrader $;{ }^{50}$ este ultimo cita tanto a Kuhn como a Toulmin. Sin embargo, como no sea para dar peso a juicios referidos a las teorías o concepciones en el campo bibliotecológico, ni Kuhn, Toulmin o Laudan, han tenido

44 Véase: Fernando Flores Camacho, Epistemología y enseñanza de la ciencia (México: UNAM, Facultad de Medicina).

45 Stephen Toulmin, La comprensión bumana. 1. El uso colectivo y la evolución de los conceptos (España: Alianza, 1977).

46 Larry Laudan, El progreso y sus problemas: hacia una teoría del crecimiento científico (España: Ediciones Encuentro, 1986).

47 Ibid., 427.

48 Robert Grover y Jack Glazier, "A Conceptual Framework for Theory Building in Library and Information Science", LISR 8, (1986): 227-242.

49 Archie L. Dick "Library and Information Science as a Social Science: Neutral and Normative Conceptions”, Library Quarterly 65, no. 2, (1995): 216-35.

50 Lavin M. Shrader, "In Search of a Name: Information Science and Its Conceptual Antecedents", LISR 6, (1984): 248. 
repercusiones importantes para la enseñanza de la bibliotecología. En otras disciplinas como la biología o la física, cuando menos Kuhn y Laudan han permitido elaborar diferentes perspectivas de enseñanza.

Conviene ahora revisar algunas de las directrices que nos importa establecer para la enseñanza de la bibliotecología con un enfoque de disciplina teórica.

\section{A. La bibliotecología se construye a partir de fenómenos, conceptos y teorías}

Dado que existe una larga tradición de enseñanza de la bibliotecología, desde la perspectiva de educación técnica, visualizarla como una disciplina con entidades y problemas teóricos que le son propios, y que trascienden las prácticas sociales y fenoménicas en que comúnmente se le ha inscrito, enfrenta en lo inmediato el problema de comprenderla con una concepción de ciencia adecuada, pues al centrarse la enseñanza bibliotecológica en las técnicas y la solución de problemas prácticos, ha quedado fuera la necesidad de enseñar teoría bibliotecológica explicativa, ya que básicamente se ha hecho uso de la teoría normativa o prescriptiva, gran parte de la cual está condensada en el "quadrivium" al que hace referencia Saracevic: 1. Selección de materiales, 2. Catalogación y clasificación, 3. Referencia y 4. Administración de bibliotecas. $^{51}$

Por lo anterior, una concepción amplia de ciencia en el sentido explicativo del término no se ha dado en la enseñanza de la disciplina. Incluso, es plausible considerar que cuando los estudiantes o profesores, vinculados estos últimos por su actividad a la práctica profesional de la disciplina bibliotecológica, presentan sus ideas sobre el quehacer de la ciencia, muchas veces poseen concepciones confusas o estereotipadas.

Kuhn planteó que la imagen de sentido común difundida sobre el desarrollo de la ciencia consiste en considerar que su progreso se basa en descubrimientos e inventos individuales, acumulativos y graduales. ${ }^{52}$ Asimismo, Kuhn resaltaba que en dicha imagen el científico es:

... una persona que está sin compromisos detrás de la verdad. Es el explorador de la naturaleza, el hombre que rechaza los prejuicios en el umbral de su laboratorio, que reúne y examina los hechos desnudos y objetivos, y que es fiel a los hechos y sólo a ellos. Estas son las características que hacen tan valioso el testimonio de los científicos cuando se hace una campaña publicitaria en los Estados Unidos. Ni si-

51 Tefko Saracevic, “Closing of Library in North America: What Role Accreditation?”, en Libri 44, no. 3 (1994): 195. Señala que así fue nombrado por Shera.

52 T. S. Kuhn, La estructura de las revoluciones científicas (México: FCE, 1971), 23 
quiera para un público internacional se requiere más. Ser científico es, entre otras cosas, objetivo e imparcial. ${ }^{53}$

No contamos a la fecha con estudios en el campo bibliotecológico que nos muestren cuál o cuáles son las concepciones de ciencia de los estudiantes y profesores poseen, pero no es una especulación fuera de lugar proponer que esta imagen de sentido común tenga peso en la visión de los estudiantes y profesores.

De este modo es posible considerar, al menos hipotéticamente, que si no existe una imagen realista y ordenada en la concepción de ciencia bibliotecológica incorporada en los planes de estudio de las escuelas, difícilmente podrá trascenderse el nivel fenoménico (experiencia inmediata) de profundidad de enseñanza, así como de técnicas y procedimientos.

Transformar de raíz la concepción sobre la enseñanza de la ciencia bibliotecológica comienza con el establecimiento claro de las preguntas y respuestas en que los futuros practicantes de la disciplina deben formarse y desarrollar los compromisos intelectuales, tal y como sucede en otras ciencias.

De acuerdo con Kuhn las preguntas fundamentales son las siguientes:

¿Cuáles son las entidades fundamentales de que se compone el Universo? ¿Cómo interactúan esas entidades, unas con otras, y con los sentidos? ¿Qué preguntas pueden plantearse legítimamente sobre esas entidades y qué técnicas pueden emplearse para buscar soluciones? ?4 $^{54}$

En principio, se trata de identificar las entidades que constituyen el objeto de estudio de la disciplina, así como la indagación sistemática con posibilidades realistas de desarrollar en torno de ellas y las reglas de la evidencia que tienen validez en su estudio. Comenzar el estudio de la disciplina bibliotecológica sobre esta base implica trascender la experiencia inmediata, lo puramente fenoménico, a partir del conocimiento de las estructuras conceptuales con las cuales es factible interpretar adecuadamente los fenómenos.

Como ha señalado Moulines: "Ninguna disciplina mínimamente desarrollada escapa, ni puede escapar a cierto grado de elaboración teórica; no hay ciencia sin teoría". ${ }^{55}$ En el caso de las teorías bibliotecológicas, es importante

53 T. S. Kuhn, "Los paradigmas científicos" en Estudios sobre sociología de la ciencia, comp. Barry Barnes, (España: Alianza, 1980): 79.

54 Ibid.

55 C. Ulises Moulines, "Nivel fenoménico y nivel substancial en la investigación (meta-)científica" en Filosofía moral, educación e historia: Homenaje a Fernando Salmerón (México: Facultad de Filosofía y Letras, Instituto de Investigaciones Filosóficas, UNAM, 1996): 295. Las cursivas y las comillas son de Moulines. 
tener en cuenta la experiencia y la observación directa, pero no como contenido único de la reflexión sistemática, en todo caso como un medio de control del análisis crítico. Esto debiera ser así porque como apunta Moulines:

Cualquier disciplina científica, incluso en los casos en los que "oficialmente" pretende lo contrario, busca en realidad un punto de vista que supere lo inmediato, [...] y justamente de cuenta de esta misma experiencia postulando entidades o estructuras que la trascienden, que en cierto sentido están "más allá de" o subyacen a los fenómenos. Ello es así incluso cuando esos fenómenos aparecen descritos no ya en "estado puro" (si es que existe tal cosa), sino subsumidos bajo ciertos esquemas más o menos sistemáticos o incluso leyes generales, es decir, [...] como entidades determinadas a cierto nivel de abstracción. ${ }^{56}$

Sobre la base de lo expuesto por Kuhn y Moulines, las preguntas centrales a las que debiera responder la formación en bibliotecología desde la perspectiva que nos interesa son las siguientes:

1. ¿Cómo opera y cómo está constituido el objeto de estudio de la bibliotecología?

2. ¿Cómo son y cómo operan las teorías bibliotecológicas?

La respuesta a tales preguntas consiste en señalar que es a partir del carácter explicativo de la disciplina. Toulmin ha subrayado el carácter de empresa racional colectiva de la ciencia cuyo objetivo común es justamente este carácter explicativo, ${ }^{57}$ que permite distinguirla de otras empresas racionales que se orientan a ideales técnicos, o bien ideales prácticos, como son las técnicas o las artesanías.

Desde la perspectiva de Toulmin, la naturaleza de una disciplina intelectual siempre incluye a sus conceptos y, también, a los hombres que los conciben, a su objeto de estudio y a las ambiciones intelectuales más amplias que une a los hombres que trabajan en ella. ${ }^{58}$

Los estudiantes que se inician en el aprendizaje de una ciencia, en este caso la bibliotecología, deberán emplear una serie de expresiones que sólo son inteligibles dentro de la disciplina. Esto es así porque las disciplinas científicas se caracterizan, según Moulines:

56 Ibid., 295-6.

57 Toulmin, Stephen, La comprensión humana: El uso colectivo y la evolución de los conceptos T.1. (España: Alianza, 1977): 369.

58 Ibid., 164. 
... por el uso de un vocabulario específico, de ciertas palabras y expresiones que no son del acervo común de los lenguajes comúnmente hablados, sino que son introducidas esencialmente en un contexto científico. El sentido de tales términos no puede ser apresado plenamente si no se tiene un conocimiento mínimo de la disciplina en que aparecen. No nos referimos aquí a expresiones procedentes del lenguaje matemático puro (expresiones aritméticas, geométricas o algebraicas, por ejemplo), sino a términos que tienen o pretenden tener una referencia en la realidad empírica, pero cuyo manejo adecuado es muy difícil, cuando no imposible, para personas que no estén suficientemente entrenadas en la disciplina en la que aparecen. ${ }^{59}$

La importancia de que los estudiantes de bibliotecología posean un conocimiento sólido de los conceptos, radica no en que tengan un origen científico, sino que su uso "sólo puede estar sancionado por una teoría científica, y que sólo quien conozca bien esa teoría, podrá hacer un uso genuino de ellos" ${ }^{60}$ De modo que el uso legítimo de los conceptos implica el conocimiento riguroso de las teorías constitutivas de la bibliotecología.

Sin embargo, el uso correcto de conceptos y manejo adecuado de las teorías bibliotecológicas, debe observarse en un contexto más general de formación del aprendiz de la disciplina. Según Toulmin la transmisión "característica de una ciencia consiste - necesariamente - en los aspectos comunales o $<<$ públicos $>>$ de sus conceptos" ${ }^{61}$ En este aprendizaje, el núcleo de la transmisión, dice Toulmin:

... el elemento primario que debe ser aprendido, probado, aplicado, criticado y cambiado es el repertorio de técnicas, procedimientos explicativos y habilidades intelectuales y métodos de representación que se emplean para $<<$ dar explicaciones $>>$ de sucesos y fenómenos dentro del ámbito de la ciencia involucrada. Para mostrar públicamente - y probar — su comprensión de los poderes explicativos de su ciencia, el recién llegado debe, ante todo, aprender cómo y cuándo aplicar esas técnicas y procedimientos de modo de explicar fenómenos que caen dentro del ámbito corriente de la ciencia. ${ }^{62}$

59 C. Ulises Moulines, "Conceptos teóricos y teorías científicas" en La ciencia: estructura y desarrollo (Enciclopedia Iberoamericana de Filosofía, t. 4): 147.

60 Ibíd., 148. Una clasificación básica de los conceptos científicos que propone es: 1. Conceptos métricos o magnitudes, 2. Idealizaciones o conceptos ficcionales y 3. Términos con referente real, pero inobservable por principio.

61 Toulmin, Stephen, La comprensión bumana: El uso colectivo y la evolución de los conceptos T.1. (España: Alianza, 1977): 168.

62 Ibid., 168-9. 
De este modo, e interpretando al autor antes citado, la transmisión intelectual de la bibliotecología, que es la herencia común que todos los practicantes de esta disciplina colectivamente aprenden, aplican y critican, abarca un conjunto de procedimientos explicativos. Al dar evidencia que se sabe cuándo y cómo aplicar esos procedimientos, se ofrece la prueba necesaria, para fines profesionales de que se ha llegado a comprender conceptualmente a la disciplina.

El ejemplo que utiliza Toulmin es el siguiente: cuando un estudiante de física aprende la significación del concepto "energía", básicamente aprendió a hacer tres cosas: 1. a efectuar los cálculos que encarnan la aritmética de la conservación de la energía, 2 . a reconocer los problemas y situaciones particulares a los que son atinentes tales cálculos, y 3. a identificar las magnitudes empíricas que entran propiamente en tales cálculos de conservación. ${ }^{63}$

Sin embargo, los conceptos científicos son complejos y en su estudio deben distinguirse tres aspectos: 1. el lenguaje, 2. las técnicas de representación, y 3. los procedimientos de aplicación de la ciencia. En el análisis de los conceptos y las teorías bibliotecológicas estos aspectos debieran abordarse de modo sistemático, todo ello para vislumbrar la fecundidad explicativa tanto de los conceptos como de las teorías. Términos como: "obra", "documento", "usuario" o "ciclo de vida de la información", etc., son entidades teóricas que presentan las tres características a las cuales nos hemos referido antes, ya que están expresadas en un leguaje especializado, son susceptibles de representación y abstracción e incluso, es factible identificar las magnitudes empíricas a las que se refieren.

$\mathrm{Al}$ ser la bibliotecología una disciplina teórica conceptualmente articulada ${ }^{64}$ producto de una empresa colectiva y racional, el estudiante de esta disciplina debería identificar la mejora en los procedimientos explicativos y no aprender las teorías como sistemas de proposiciones autosuficientes y estáticos, pues como bien señala Toulmin:

Lo que señala como racional a la obra de un científico no es su competencia para la manipulación formal de conceptos y argumentos establecidos, sino su disposición a concebir, explorar y criticar nuevos conceptos, argumentos y técnicas de representación, como maneras de abordar los problemas principales de su ciencia. ${ }^{65}$

63 Ibid., 169.

64 Un estudio interesante sobre el carácter lógico y lingüístico, en el caso de la documentación, el cual explora ampliamente una de las dimensiones básica de la racionalidad en que descansa esta disciplina, puede verse en: Felix Sagredo y José María Izquierdo, Concepción lógico-lingüistica de la documentación (Madrid: Ibercom - Red Comnet de la UNESCO, 1983).

65 Ibid., 375. 
Uno de los rasgos esenciales de la ciencia es su carácter de autocrítica. Es importante que los estudiantes identifiquen este rasgo y que lo practiquen, probando el valor de verdad de los conceptos y teorías bibliotecológicas. Según da Costa: "las teorías científicas son formuladas para ser superadas y, algunas veces, totalmente abandonadas, incluso cuando han funcionado por largo tiempo". ${ }^{66}$

En suma, para esta directriz metodológica de enseñanza de la bibliotecología se vincula directamente con el carácter teórico y racional de la disciplina. El punto esencial de esta racionalidad reside en su fundamento conceptual. Para trabajar esta directriz es necesario transformar la concepción de enseñanza técnica que ha privado e introducir a los estudiantes en las preguntas fundamentales de la disciplina, sus conceptos y teorías, así como en su carácter de empresa autocrítica y autocorrectiva.

\section{B. La historia intelectual de los conceptos y las teorías bibliotecológicas}

Kuhn en la Estructura de las revoluciones científicas, específicamente en el primer capítulo titulado "Introducción: un papel para la historia," plantea las premisas básicas para abordar la historia de la ciencia y el trabajo del historiador. Kuhn señala que con base en los estudios historiográficos es posible transformar la imagen de la ciencia, la cual ha sido heredada a través de los libros de texto, cuyo sentido persuasivo y pedagógico, está fuertemente limitado para mostrar el desarrollo científico en una perspectiva realista y diferente.

Kuhn también considera que la historia de la ciencia debe abordarse poniendo de manifiesto "la integridad histórica de esa ciencia en su propia época" ${ }^{67}$ haciéndose preguntas sobre la relación existente entre sus opiniones y las de sus maestros, contemporáneos y sucesores "que concede a esas opiniones la máxima coherencia interna y el ajuste más estrecho posible con la naturaleza”. ${ }^{68}$ Particularmente indica Kuhn que

"la construcción de una imagen diferente de la ciencia toma como punto de partida la insuficiencia de las directrices metodológicas para orientar diferentes preguntas científicas y al revisar el desarrollo de las primeras etapas de las ciencias se hace evidente una competencia continua entre diferentes concepciones, derivadas parcialmente de la observación y del método científico. Las diferencias estaban

66 Newton C. A. da Costa, El conocimiento científico (México: UNAM, Instituto de Investigaciones Filosóficas, 2000): 50. 
dadas por sus "modos inconmensurables de ver el mundo y de practicar en él las ciencias". 69

Con base en estas consideraciones de orden metodológico es factible que los estudiantes de bibliotecología aborden cada uno de los conceptos, redes conceptuales y teorías bibliotecológicas, así como los fenómenos que forman parte de su dominio. Por ejemplo, Schrader ${ }^{70}$ realizó un importante estudio de los antecedentes conceptuales de ciencia de la información (Information Science) y cronológicamente ordena las principales escuelas de pensamiento, del modo siguiente:

Términos de ciencia de la información y sus antecedentes

\begin{tabular}{ll}
\hline 1900s a 1930s & Bibliografía \\
1920s a 1950s & Documentación \\
1940s a 1950s & Información científica \\
1950 s a 1960s & Recuperación de información \\
$1960 s$ & Ciencia de la información \\
$1970 s$ & Bibliometría \\
\hline
\end{tabular}

Fuente: Lavin M. Shrader, "In Search of a Name: Information Science and Its Conceptual Antecedents”, LISR 6, (1984): 231.

El estudio se publicó en 1984 y con base en el tiempo transcurrido, así como la evolución conceptual de la bibliotecología y los cambios terminológicos en la literatura de la disciplina, el cuadro es incompleto y anacrónico, además comete el error de incluir a la bibliometría como un campo disciplinario del mismo nivel o naturaleza que la documentación. Asimismo, la omisión del concepto de bibliotecología es la falla más grave en este resumen que propone Schrader.

No obstante, y dado que sólo se trata de un ejemplo, el texto permite delimitar históricamente el predominio conceptual de las escuelas de pensamiento antes mencionada, en una perspectiva diacrónica. Tomando como base el criterio de analizar la integridad histórica de esa ciencia en su propia época, según lo expresa Kuhn, es importante que los estudiantes profundicen en las discusiones teóricas de la época, así como los problemas conceptuales y los vacíos cognoscitivos que han enfrentado las teorías bibliotecológicas y sus antecedentes. De este modo, la perspectiva diacrónica permitirá comprender a los estudiantes las variaciones conceptuales y cambios teóricos. Por otra

69 Ibid., 25.

70 Lavin M. Shrader, "In Search of a Name: Information Science and Its Conceptual Antecedents”, LISR 6, (1984): 231. 
parte, el estudio sincrónico permitirá profundizar en el origen y la comprensión de los conceptos y teorías bibliotecológicas, explicitando los referentes empíricos de los conceptos y las explicaciones de los fenómenos que en una determinada época planteaba preguntas cognoscitivamente relevantes a los teóricos de la bibliotecología.

El estudio de la obra de autores como Dewey, Shera, Bradford, Otlet, Ranganathan, por citar sólo algunos, permitiría establecer a los estudiantes la genealogía conceptual de mayor peso epistémico en la disciplina bibliotecológica. No obstante, la historia intelectual de la bibliotecología que también sería importante estudiar, es aquella que nos ofrezca el relato sobre las "revoluciones científicas" en el campo bibliotecológico, que de acuerdo con Kuhn tendría que explicarnos:

1. ¿Cómo surgió y fue reconocida una teoría bibliotecológica? ¿Cómo fue rechazada la teoría bibliotecológica contrincante?

2. ¿Cuáles fueron los cambios en los problemas teóricos y empíricos disponibles y admisibles para el análisis científico y soluciones legítimas?

3. ¿Cómo se llevó a cabo la transformación de la imaginación y del mundo bibliotecológico en que se realizaba el trabajo científico y cuáles fueron las controversias que generó?

Como ya se ha mencionado, los estudiantes de una disciplina se vinculan a una herencia cognoscitiva. El estudio de la historia de la disciplina bibliotecológica permitirá reconstruir y reinterpretar, en una perspectiva más objetiva y realista, el quehacer de la disciplina en cuanto a la constitución de sus problemas y las entidades teóricas que ha postulado.

En el análisis histórico de la evolución intelectual de la disciplina bibliotecológica, también es posible que los estudiantes aborden las tradiciones de investigación que en ella han proliferado. Según Laudan las tradiciones de investigación constan de los siguientes componentes:

1. Un conjunto de creencias acerca de qué tipos de entidades y procesos constituyen el dominio de la investigación

2. Un conjunto de normas epistémicas y metodológicas acerca de cómo tienen que investigarse ese dominio, es decir, principios metodológicos de amplio alcance vinculados a técnicas experimentales, modos de corroboración empírica y evaluación de teorías y otros aspectos similares.

Estos componentes de las tradiciones de investigación están estrechamente relacionados porque "los puntos de vista acerca de los métodos de 
indagación adecuados son generalmente compatibles con los puntos de vista sobre los objetos de indagación". ${ }^{71}$ De forma más sintética Laudan señala que

"una tradición de investigación es un conjunto de supuestos generales acerca de las entidades y procesos de un ámbito de estudio, y acerca de los métodos apropiados que deben ser utilizados para investigar los problemas y construir las teorías de ese dominio". ${ }^{72}$

Las funciones especificas que las tradiciones de investigación cumplen, son las siguientes: 1. Indican qué supuestos serán considerados como "conocimiento de fondo", es decir, se da por válido y no está sujeto a discusión por los investigadores que forman parte de esa tradición, 2. Auxilian para identificar las partes de la teoría que tienen problemas y deben ser corregidas, 3 . Indican las reglas para la recogida de datos y la prueba de las teorías, 3. Señalan los problemas conceptuales a las teorías de la tradición toda vez que viole los postulados ontológicos y epistémicos de la misma.

Laudan también indica que:

Comparadas con las teorías individuales, las tradiciones de investigación tienden a ser entidades persistentes. Así como las teorías pueden ser abandonadas y sustituida con mucha frecuencia, las tradiciones de investigación suelen ser longevas, dado que, obviamente, pueden resistir la defunción de cualquiera de sus teorías subordinadas. Las tradiciones de investigación son las unidades que perduran a través del cambio de teorías, y que establecen, junto con los problemas empíricos resueltos, gran parte de lo que de continuidad hay en la historia de la ciencia. Pero incluso las tradiciones de investigación pueden ser destronadas. ${ }^{73}$

Laudan afirma que para explicar la empresa científica la regla no es la sustitución de un paradigma por otro. Más bien, la regla es la coexistencia de tradiciones de investigación rivales. Menciona que lo frecuente es que las disciplinas científicas engloben diversas perspectivas científicas copresentes y agrega:

En cualquier momento dado, puede una u otra de estas cobrar ventaja en la disputa, pero sigue teniendo lugar una lucha continua y persistente, en la que los partidarios de uno y otro punto de vista señalan las debilidades empíricas y conceptuales

71 Larry Laudan, El progreso y sus problemas: Hacia una teoría del crecimiento científico (España: Encuentro, 1986), 116. Las cursivas son de Laudan

72 Ibid. Las cursivas son de Laudan.

73 Ibid., 19. 
de los rivales y subrayan la progresividad de su propio enfoque en la resolución de problemas. Las confrontaciones dialécticas son esenciales para el avance y el perfeccionamiento del conocimiento científico; como la naturaleza, la ciencia tiene los dientes y las garras rojas. ${ }^{74}$

Como lo normal es la coexistencia y luchan entre teorías rivales, sobre la base de la elección de teorías más progresivas, será también el pluralismo teorético que contribuye al progreso científico. A este fin contribuyen las tradiciones científicas.

En el caso de la bibliotecología, es posible abordarla considerando que está constituida por diferentes teorías o tradiciones de investigación y que cada una de ellas se ha orientado a resolver problemas de carácter empírico y conceptual. Además, algunas de ellas han tenido mayor éxito para resolver los problemas.

Un enfoque de esta naturaleza es más pertinente para que los estudiantes comprendan cómo es posible que coexistan tradiciones de investigación totalmente instituidas en la disciplina bibliotecológica y que continúen reconociéndose en ellas.

En esta perspectiva cobra especial relevancia el conocimiento que los estudiantes tengan de las revistas académicas en que dichas tradiciones de investigación se expresan. También porque en ellas se muestran los problemas que cognoscitivamente se consideran relevantes y las soluciones que han logrado alcanzarse. Es decir, el estudiante de bibliotecología debe acercarse a la indagación sistemática de la disciplina y sus productos. En síntesis se menciona que la directriz metodológica consiste en introducir al alumno en el análisis de los cambios teóricos más importantes que se hayan dado en la bibliotecología, así como identificar las tradiciones de investigación que en ella coexisten.

\section{El cambio conceptual en los estudiantes de bibliotecología}

Las directrices expuestas en los apartados anteriores están orientadas a comprender la naturaleza y desarrollo de la disciplina bibliotecológica. La siguiente directriz propone la teoría del cambio conceptual como una poderosa herramienta de trabajo en la construcción de los conceptos bibliotecológicos que podrían llevar a cabo los estudiantes. Aunque en las últimas dos décadas esta teoría ha tenido aplicaciones interesantes en otras disciplinas, a la fecha no se han identificado este tipo de estudios en la literatura bibliotecológica. 
Desde el marco del constructivismo, ${ }^{75}$ se han tenido aportaciones fundamentales para analizar y proponer mejoras a la enseñanza de las ciencias. ${ }^{76} \mathrm{Las}$ dos premisas esenciales de las cuales parte son las siguientes: 1. la mente juega un papel activo en la construcción del conocimiento, y 2. los conceptos son inventados por los sujetos más que descubiertos. De acuerdo con Flores el supuesto básico del constructivismo consiste en lo siguiente: la actividad del conocimiento es un proceso el cual es necesario construir, estructurar y dar significado. ${ }^{77}$

La construcción de los conceptos científicos es un proceso complejo, porque en primera instancia implica superar las preconcepciones o concepciones intuitivas que los estudiantes han elaborado. Flores explica que las preconcepciones poseen tres características básicas: ${ }^{78}$

a) Son elaboraciones conceptuales independientes del contexto escolar. Esto implica, en general, que no son influidas por la escuela. Se trata de elaboraciones que dependen de la interpretación de la interacción cotidiana con la realidad y que, en forma parcial, son elementos de explicación funcional de la misma.

b) Son resistentes a la acción escolar. (...)

c) Forman un esquema conceptual paralelo al escolar. Esto es claro puesto que los estudiantes desarrollan habilidades específicas para la solución de problemas y cierto nivel de competencia en el manejo del lenguaje científico. Sin embargo, cuando se les cuestiona de forma no escolarizada, o bien, se piden sus interpretaciones sobre cierta fenomenología, el sistema que opera es el personal desvinculado del escolar.

Existe abundante bibliografía que muestra cómo las preconcepciones de los estudiantes se presentan en diferentes campos de la ciencia y que se integran en la mente de éstos robustamente y que, además, tales concepciones son capaces de sobrevivir a la enseñanza que las contradice. ${ }^{79}$

Es por tanto sobre la base del conocimiento de las preconcepciones de los estudiantes de bibliotecología y la confrontación cognoscitiva en que sería posible llevar a cabo la enseñanza de esta ciencia.

75 Kenneth Tobin y Deborah Tippins, "Constructivism as a Referent for Teaching and Learning" en The Practice of Constructivism in Science Education (UK: Laurence Erlbaum, 1993).

76 J. I. Pozo y M. A. Crespo, Aprender y enseñar ciencia: del conocimiento cotidiano al conocimiento cientifico (España: Morata, 1998).

77 Fernando Flores Camacho, Epistemología y enseñanza de la ciencia (México: UNAM, Facultad de Medicina, Seminarios Institucionales 10, 1994): 8.

78 Ibíd., 10. Véase también los estudios inicales en este campo de: R. Driver y G. Erickson, "Theories in action: Some theoretical and empirical issues in the study of students' conceptual frameworks in science" Studies in Science Education 10, (1983): 37-60; R. J. Osborne y M. C. Wittrock, "Learning science: A generative process" Science Education 67, no. 41 (1983): 489-508.

79 J. I. Pozo y M. A. Crespo, Aprender y enseñar ciencia: Del conocimiento cotidiano al conocimiento científico (España: Morata, 1998): 97. 
De acuerdo como fue postulada la teoría del cambio conceptual, ${ }^{80}$ la cuestión básica es considerar cómo cambian las ideas de los estudiantes de bibliotecología al sufrir el impacto de las nuevas ideas y de las nuevas evidencias.

El cambio abarca dos fases:

1. Asimilación. Los estudiantes utilizan conceptos ya existentes para trabajar nuevos fenómenos.

2. Acomodación. Los conceptos preexistentes en los estudiantes son inadecuados para permitirle captar los fenómenos satisfactoriamente, entonces se deben reemplazar o reorganizar sus conceptos centrales.

Condiciones para que la fase de acomodación se realice:

1. Debe existir insatisfacción con las concepciones existentes.

2. Una concepción nueva debe ser mínimamente sobreentendida.

3. Una concepción nueva debe parecer inicialmente plausible.

4. Una concepción nueva podría sugerir las posibilidades de un programa de trabajo intelectual fructífero.

De acuerdo con Strike y Posner, ${ }^{81}$ los conceptos de una persona influyen en la selección de un nuevo concepto central. Algunos de los conceptos que se han identificado como determinantes para orientar la acomodación, son:

1. Anomalías. El carácter de los fracasos específicos de una idea dada.

2. Analogías y metáforas. Estas pueden servir para sugerir nuevas ideas y hacerlas comprensibles.

3. Ideales exploratorios. La mayoría de las disciplinas tienen ideas específicas sobre lo que es una explicación satisfactoria

4. Concepciones en competencia. Una condición para la selección de un nuevo concepto es que pueda tener la apariencia de que cuenta con más promesas que sus competidoras.

El nuevo conocimiento de la disciplina bibliotecológica debe integrarse y modificar las condiciones en que se encontraban las concepciones previas de los estudiantes, a fin de que el nuevo conocimiento sea realmente novedoso y original en la mente del sujeto.

80 K. Strike y G. Posner, "A conceptual change view of learning and understanding" en Cognitive Structures and Conceptual Change, L. Pines y L. West., Eds. (EU: Academic Press Orlando, 
De lo antes expuesto sobre la teoría del cambio conceptual se desprende que el contenido de las asignaturas de bibliotecología debe ser tal que las teorías y conceptos implicados debieran trabajarse en el plano de inteligibilidad, el carácter verosímil de las teorías y conceptos bibliotecológicos, así como el sentido fructífero que brindan en el intelecto de los estudiantes.

Asimismo se requiere que haya mayor énfasis en los procesos de asimilación y acomodación, más que en el "temario" o carga de contenidos. Sin embargo, para que no sea exclusivamente un proceso de asimilación sin llegar a concretarse la fase de acomodación es imprescindible recurrir y generar el conflicto cognitivo, pues juega este un papel crucial en tales procesos, pero el campo fértil para el conflicto se abona en gran medida con las teorías y los conceptos de la disciplina bibliotecológica. El resultado final del conflicto cognitivo es lograr que la construcción de las entidades teóricas y conceptuales por parte de los alumnos sean coherentes y congruentes con la disciplina.

\section{Conclusiones}

Al igual que sucede con los procesos individuales de adquisición de conocimiento, es importante que para transformar la idea de la enseñanza de la bibliotecología como técnica o técnicas, se opere un cambio conceptual hacia una concepción articulada y coherente que le corresponde como disciplina teórica. Lo anterior no implica rechazar la relevante función social que cumple la bibliotecología a través de sus aplicaciones prácticas.

Las directrices expuestas tienen la finalidad de desarrollar en los futuros practicantes de la disciplina bibliotecológica la conciencia sobre este carácter conceptual, teórico, histórico y de tradiciones de investigación que en ella coexisten. Asimismo, buscan lograr la exigencia de coherencia y compromiso intelectual con las teorías y conceptos, así como la conciencia de la carga epistémica de los conceptos y teorías bibliotecológicas, y su desarrollo histórico. Lo anterior dota de mejores instrumentos cognoscitivos a los estudiantes y hace más fructífera la enseñanza de los docentes. A mejor comprensión de la teoría corresponde una mejor práctica y con ello los futuros practicantes de la bibliotecología estarán en condiciones intelectuales superiores para responder asertivamente al cambiante mundo fenoménico de la bibliotecología y la realidad social.

Las directrices básicas enunciadas no tienen el propósito de formar investigadores en el pregrado o licenciatura; simplemente se pretende apoyar la enseñanza de la disciplina bibliotecológica con una de las armas más poderosas del intelecto humano, la racionalidad, que al igual que ha sucedido con 
otras ciencias, ha permitido su construcción. El desarrollo y aplicación de estas directrices implica analizar críticamente el tipo de enseñanza predominante de modo tal que se trascienda el nivel fenoménico de la práctica bibliotecológica hacia el nivel teórico y de abstracción de la disciplina; es decir, que se trabaje la construcción del aprendizaje con las teorías y conceptos bibliotecológicos, que en esencia son el producto más refinado de la disciplina. Pero esta construcción requiere del conflicto cognitivo, esto es, de la indagación crítica y correctiva respecto a lo que el estudiante de bibliotecología considera válido y suficientemente explicativo. Sin embargo el conflicto cognitivo como tal, es un medio para promover los procesos de acomodación cuyo resultado consiste en la reconstrucción sistemática y congruente de las teorías y conceptos bibliotecológicos con la disciplina. Al mismo tiempo, también es posible trabajar este conflicto cognitivo en el ámbito de la historia intelectual de la disciplina, tomando como punto de partida los vacíos cognoscitivos y la evolución de las concepciones que han permitido describir y explicar los fenómenos bibliotecológicos. Éste y no otro es el carácter complementario de las directrices. El redimensionamiento teórico de la bibliotecología es un proceso activo cuya naturaleza es parecida al aprendizaje de los estudiantes. Por lo tanto, profundizar en la aplicación de las directrices antes descritas nos llevará a comprender con mayor profundidad los problemas propios de la enseñanza de la bibliotecología, finalmente, nos permitirá realizar procesos formativos más éxitos y más acordes con las perspectivas sólidas de la enseñanza de la ciencia, que los que actualmente existen.

\section{Bibliografía}

La teoría en la educación bibliotecológica: directrices básicas para su enseñanza

1. "American Library Association's Standards for Accreditation of Master's Programs in Library \& Information Studies", en Larry J. Ostler, Therrin C. Dahlin y J.D. Willardson, The Closing of American Library Schools: Problems and Opportunities. USA: Greenwood Press, 1995: 83-91.

2. Auld, Lawrence W.S., "Seven Imperatives for Library Education", en Library Journal, may 1 (1990): 55-59.

3. Becker, Nancy J., Elizabeth B. Pollicino y Dennis H. Holtshneider, C.M., Challenges in Librarianship: A Casebook for Educators and Professionals, USA: Scarecrow Press, 2003.

4. Bruner, Gerome, El proceso de la educación. México: UTHEA, 1963.

5. Butler, Pierce, Introducción a la biblioteconomía, México: Pax, 1971. 
6. Contreras Domingo, José, Enseñanza, currículum y profesorado: Introducción crítica a la didáctica. España: Akal, 1994.

7. Da Costa Newton C.A., El conocimiento científico, México: UNAM, Instituto de Investigaciones Filosóficas, 2000.

8. Danton, Periam, La formación profesional del bibliotecario. París: UNESCO, 1950.

9. Díaz Barriga, Ángel, "La investigación en el campo de la didáctica: Modelos históricos”, en Perfiles Educativos 20, núm. 70-80: 5-25.

10. Dick, Archie L., "Library and Information Science as a Social Science: Neutral and Normative Conceptions", en Library Quarterly 65, no. 2, (1995): 216-235.

11. Flores Camacho, Fernando, Epistemología y enseñanza de la ciencia, México: UNAM, Facultad de Medicina, Seminarios Institucionales 10, 1994.

12. Gorman, G. E. “The Future for Library Science Education”, en Libri 46 (1999): 1-10.

13. Grover Robert y Jack Glazier, "A Conceptual Framework for Theory Building in Library and Information Science", en LISR 8, (1986): 227-242.

14. Guidelines for Curriculum Development in Information Studies, París: UNESCO, UNISIS, 1978.

15. Kansanen, Pertti. "La Deutsche Didaktik”, en Revista de Estudios del Curriculum 1, núm. 1, (1998): 13-20.

16. Kuhn T. S., La estructura de las revoluciones cientificas, México: FCE, 1971.

17. ____________ "Los paradigmas científicos", en Estudios sobre sociología de la ciencia. Comp. Barry Barnes, España: Alianza, 1980.

18. Lafuente López, Ramiro y Estela Morales Campos, "Reflexiones en torno a la enseñanza de la bibliotecología”, en Investigación bibliotecológica 6, no. 12 (enero-junio 1992):

19. Laudan, Larry, El progreso y sus problemas: hacia una teoría del crecimiento científico, España: Ediciones Encuentro, 1986.

20. Library Trends 45, num. 2 (1996).

21. Morales Campos, Estela, Educación bibliotecológica en México 1915 - 1954, México: UNAM, CUIB, 1989.

22. _________Por qué estudiar bibliotecología?, Ponencia presentada en la XVII Reunión del Consejo para Asuntos Bibliotecarios, Universidad Autónoma de Baja California Sur, 26 al 28 de abril de 2001.

23. Morehead, Joe, Theory and Practice in Library Education, USA: Libraries Unlimited, 1980.

24. Moulines, C. Ulises, "Conceptos teóricos y teorías científicas", en La ciencia: estructura y desarrollo, Enciclopedia Iberoamericana de Filosofía. T. 4: 147-162.

25. Moulines, C. Ulises, "Nivel fenoménico y nivel substancial en la investigación (meta-) científica”, en Filosofía moral, educación e bistoria: Homenaje a Fernando Salmerón, México: Facultad de Filosofía y Letras, Instituto de Investigaciones Filosóficas, UNAM, 1996: 295-304. 
26. Nassif, Ricardo, "Fundamentos de pedagogía y metodología: Estudio preliminar para una pedagogía bibliotecológica”, en Josefa E. Sabor, Métodos de enseñanza de la bibliotecología. París: UNESCO, 1968.

27. Ostler, Larry J., Therrin C. Dahlin y J.D. Willardson, The Closing of American Library Schools: Problems and Opportunities, USA: Greenwood Press, 1995.

28. Pemberton Michael, J. y Cristine R. Nugent, "Information Studies: Emergent Field, Convergent Curriculum”, en Journal of Education for Library and Information Science 36, no. 2 (spring 1995): 126-38.

29. Pozo J. I. y M. A. Crespo, Aprender y enseñar ciencia: del conocimiento cotidiano al conocimiento científico, España: Morata, 1998.

30. Rehman, Sajad ur, Preparing the Information Professional: An Agenda for the Future, USA: Greenwood Press, 2000.

31. Rodríguez Gallardo, Adolfo, La formación bumanista del bibliotecario: hacia su recuperación, México: UNAM, CUIB, 2001.

32. Sabor, Josefa E., Métodos de enseñanza de la bibliotecología, París: UNESCO, 1968.

33. Sagredo, Felix y José María Izquierdo, Concepción lógico-lingüística de la documentación, Madrid: Ibercom - Red Comnet de la UNESCO, 1983.

34. Saracevic, Tefko, "Closing of Library in North America: What Role Accreditation?", en Libri 44, no. 3 (1994): 194-95.

35. Shera, Jesé, Fundamentos de educación bibliotecológica, México: UNAM, CUIB, 1990.

36. Shrader, Lavin M., "In Search of a Name: Information Science and Its Conceptual Antecedents", en LISR 6, (1984): 227-271.

37. Stieg, Margaret F., Change and Challenge in Library and Information Science Education, USA: American Library Association, 1992.

38. Stöker, Kart, Principios de didáctica moderna, Argentina: Kapelusz, 1964.

39. Strike K. y G. Posner. "A conceptual change view of learning and understanding”, en Cognitive Structures and Conceptual Change, L. Pines y L. West., Eds., EU: Academic Press Orlando, 1985: 211-231.

40. Thompson, Antonhy H., Guía para la producción y la utilización de medios audiovisuales en la enseñanza de la bibliotecología y ciencia de la información, París: UNESCO, Programa General de Información y UNISIST, 1983.

41. Tobin Kenneth y Deborah Tippins, "Constructivism as a Referent for Teaching and Learning", en The Practice of Constructivism in Science Education. UK: Laurence Erlbaum, 1993.

42. Toulmin, Stephen, La comprensión bumana, 1. El uso colectivo y la evolución de los conceptos, España: Alianza, 1977. 